Maria Luiza Gorga

A FUNÇÃO DA MEMÓRIA NA APLICAÇÃO DO DIREITO PENAL

TESE DE DOUTORADO

Orientador: Prof. Doutor Roberto Augusto de CARVAlHo CAMPOS

Faculdade de Direito da Universidade de São Paulo São Paulo

2019 


\section{Maria Luiza Gorga}

A FUNÇÃO DA MEMÓRIA NA APLICAÇÃO DO DIREITO PENAL

Tese apresentada à Banca Examinadora do

Programa de Pós-Graduação em Direito, da Faculdade de Direito da Universidade de São Paulo, como exigência parcial para a obtenção do título de Doutor em Direito na área de concentração de Direito Penal, Medicina Forense e Criminologia, sob a orientação do Professor Doutor Roberto Augusto de Carvalho Campos.

\section{Faculdade de Direito da Universidade de São Paulo SÃo Paulo}




\section{Catalogação da Publicação \\ Serviço de Biblioteca e Documentação \\ Faculdade de Direito da Universidade de São Paulo}

Gorga, Maria Luiza

A função da memória na aplicação do direito penal ; Maria Luiza Gorga ; orientador Roberto Augusto de Carvalho Campos -- São Paulo, 2019.

97

Tese (Doutorado - Programa de Pós-Graduação em Direito Penal, Medicina Forense e Criminologia) - Faculdade de Direito, Universidade de São Paulo, 2019.

1. neurociência. 2. memória humana. 3. direito penal. 4. depoimento pessoal. 5. reconhecimento pessoal. I. Campos, Roberto Augusto de Carvalho, orient. II. Título. 


\title{
A FUNÇÃO DA MEMÓRIA NA APLICAÇÃO DO DIREITO PENAL
}

\author{
Tese apresentada à Banca Examinadora do \\ Programa de Pós-Graduação em Direito, da \\ Faculdade de Direito da Universidade de \\ São Paulo, como exigência parcial para a \\ obtenção do título de Doutor em Direito na \\ área de concentração de Direito Penal, \\ Medicina Forense e Criminologia, sob a \\ orientação do Professor Doutor Roberto \\ Augusto de Carvalho Campos.
}

São Paulo, de de 2019.

Nome:

Nome:

Nome:

Nome:

Nome: 
A todos os que, à sua maneira, me apoiaram por toda a jornada acadêmica. 


\section{RESUMO}

Maria Luiza Gorga. A função da memória na aplicação do direito penal. 2019. 97 pgs. Doutorado - Faculdade de Direito. Universidade de São Paulo, São Paulo, 2019.

A presente tese utiliza por base os conhecimentos da medicina, mais especificamente da chamada neurociência, e da psicologia para desenvolver um arcabouço teórico do estado atual da ciência no tocante ao desenvolvimento e formação da memória humana, bem como das falhas e vulnerabilidades destes processos. A partir destas informações, realizase a interface destas para com o direito penal brasileiro, sobretudo no tocante à obtenção de relatos de testemunhas e vítimas, demonstrando a fragilidade deste meio de prova que é ainda bastante valorizado pelos atores do Poder Judiciário. Ao final, após a análise de iniciativas estrangeiras e nacionais que visam a aumentar a qualidade dos relatos obtidos em investigações criminais, são realizadas proposições para o aprimoramento de magistrados, investigadores de polícia, e todos os atores envolvidos na persecução e julgamento de delitos.

Palavras-chave: neurociência; memória humana; direito penal; depoimento pessoal; reconhecimento pessoal. 


\begin{abstract}
Maria Luiza Gorga. The role of memory in the application of criminal law. 2019. 97 pgs. PhD - Faculty of Law. University of São Paulo, São Paulo, 2019.

The present thesis uses knowledge of medicine, more specifically the so-called neuroscience, and of psychology to develop a theoretical framework of the current state of science regarding the development and formation of human memory, as well as the flaws and vulnerabilities of these processes. Based on this information, it interfaces with Brazilian criminal law, especially in regards to obtaining reports of witnesses and victims, demonstrating the fragility of this evidence that is still highly valued by the actors of the Judiciary system. In the end, after the analysis of foreign and national initiatives aimed at increasing the quality of reports obtained in criminal investigations, proposals are made for the improvement of magistrates, police investigators, and all actors involved in the prosecution and prosecution of crimes.
\end{abstract}

Keywords: neuroscience; human memory; criminal law; personal testimony; personal identification. 


\section{SOMMARIO}

Maria Luiza Gorga. Il ruolo della memoria nell'applicazione della legge penale. 2019. 97 pg. Dottorato di ricerca - Facoltà di giurisprudenza. Università di São Paulo, São Paulo, 2019.

La presente tesi utilizza la conoscenza della medicina, più specificamente la cosiddetta neuroscienza, e della psicologia per sviluppare un quadro teorico dello stato attuale della scienza per quanto riguarda lo sviluppo e la formazione della memoria umana, nonché i difetti e le vulnerabilità di questi processi. Sulla base di queste informazioni, si interfaccia con la legge penale brasiliana, in particolare per quanto riguarda l'ottenimento di segnalazioni di testimoni e vittime, dimostrando la fragilità di questa prova che è ancora molto apprezzata dagli attori della magistratura. Alla fine, dopo l'analisi delle iniziative straniere e nazionali volte ad aumentare la qualità delle relazioni ottenute nelle indagini penali, vengono avanzate proposte per il miglioramento dei magistrati, degli investigatori di polizia e di tutti gli attori coinvolti nell'accusa e nel perseguimento dei reati.

Parole chiave: neuroscienza; memoria umana; diritto penale; testimonianza personale; riconoscimento personale. 


\section{SUMÁRIO}

INTRODUÇÃO

MÉTODO 9

1. A MEMÓRIA 15

1.1 A NEUROBIOLOGIA DO FUNCIONAMENTO DA MEMÓRIA 20

1.2 AS VERDADES E AS FALSIDADES 26

1.3 PARTICULARIDADES E LIMITAÇÕES 28

$\begin{array}{lll}\text { 1.3.1 IDADE } & 34\end{array}$

$\begin{array}{lll}\text { 1.3.2 GENERO } & 38\end{array}$

$\begin{array}{lll}\text { 1.3.3 ESTRESSORES } & 38\end{array}$

1.3.4 DOENÇAS E OUTRAS CONDIÇÕES FISIOLÓGICAS

1.3.5 USO DE SUBSTÂNCIAS PSICOATIVAS

1.4 POSSIBILIDADES DE EXPLORAÇÃO DOS MECANISMOS E SUAS FALHAS INERENTES 47

1.4.1 INDUÇÃOO

1.4.2 FALSAS MEMÓRIAS

2. A PROVA TESTEMUNHAL 56

3. EXPERIÊNCIAS: TÉCNICAS PARA A MELHORA DA FIDEDIGNIDADE DOS RELATOS 66

$\begin{array}{lll}3.1 & \text { EXPERIÊNCIAS INTERNACIONAIS } & 68\end{array}$

$\begin{array}{lll}3.2 & \text { INICIATIVA NACIONAL } & 72\end{array}$

CONCLUSÃO

BIBLIOGRAFIA

$\begin{array}{ll}\text { ANEXO I } & 91\end{array}$ 


\section{INTRODUÇÃO}

"Our fond $\mathrm{X}$ memories are the dregs left in the wineglass, the dehydrated sediments of perceptions whose flavour has gone."

O presente estudo parte de um importante questionamento: estaria a atual concepção do Direito Penal acerca da confiabilidade da prova testemunhal - e, portanto, da memória condizente com a realidade da mente humana, e haveria modos de obtenção de relatos com a maior fidedignidade possível?

Em estreita ligação com esta questão, surge também a necessidade de se questionar: há formas de se robustecer a ciência jurídica no tocante a estudos como o presente, e à sua aplicação prática?

Já foi dito pelo neurocientista americano Dean Buonomano que "Embora os mágicos e os psicólogos saibam há muito tempo que as memórias podem ser sobrescritas pela interferência de desinformação, o sistema judiciário tem sido lento em reconhecer esse fato.".

Pois é assim necessário adequar a ciência penal aos fatos. E estes são, para iniciar, e conforme o neurocientista português António Damásio, que “as imagens não são armazenadas sob forma de fotografias de coisas, de acontecimentos, de palavras ou de frases. [...] Se o cérebro fosse uma biblioteca esgotaríamos suas prateleiras à semelhança do que acontece nas bibliotecas" 3 .

\footnotetext{
${ }^{1}$ Tradução livre: "Nossas boas lembranças ' $x$ ' são os resíduos deixados no copo de vinho, os sedimentos desidratados de percepções cujo sabor desapareceu.". KOESTLER, Arthur. The Ghost in the Machine. London: Hutchinson, 1967. p. 84.

${ }^{2}$ BUONOMANO, Dean. O cérebro imperfeito. Rio de Janeiro: Elsevier, 2011. p. 44.

${ }^{3}$ DAMASIO, Antonio R. O Erro de Descartes. São Paulo: Companhia das Letras, 2012. p. 128-129.
} 
Ocorre que, infelizmente, ainda há a crença de que a memória humana é permanente, funcionando como verdadeiro gravador, e que se algo não vem imediatamente a lume é apenas questão de utilizar-se o adequado método de recuperação. ${ }^{4}$

Ora, se o julgador não leva em consideração as nuances da mente, pode-se chegar a resultados equivocados e, sobretudo, injustos - seja para o acusado, seja para a sociedade, seja para uma testemunha acusada de falsear a verdade. E isso, inobstante esteja o indivíduo convencido de seu relato, de "cuja exatidão poderia até jurar"5.

O Direito, sobretudo o Direito Penal, por sua elevada carga de interferência estatal na liberdade dos cidadãos, não pode deixar-se ficar à margem dos conhecimentos científicos, levando em conta em suas formulações os novos dados advindos da neurociência, criando um sistema de trabalho interdisciplinar. ${ }^{6}$

Há, dessa forma, necessidade de conscientização profunda de todas as esferas da classe jurídica a respeito das nuances da memória humana, de seus limites e de suas potenciais distorções, inconscientes e até mesmo inatas, de modo que se possam sopesar as declarações com o olhar crítico que merecem todos os elementos de convicção existentes no procedimento criminal. ${ }^{7}$

A neurociência - aqui entendida de forma geral como o estudo científico do cérebro e do sistema nervoso central, tanto de forma biológica como química, psicológica, etc. - vem evoluindo ao longo dos séculos. Nas décadas de 1960 e 1970 surgiram a tomografia computadorizada e a ressonância magnética, o que permitiu uma nova forma de análise neurológica, levando a novas hipóteses e estudos a respeito da consciência humana.

\footnotetext{
${ }^{4}$ Como exemplo, $2 / 3$ dos policiais americanos afirmaram acreditar que a memória humana funciona como um gravador. Cf.: LYNN, Steven Jay et al. What Do People Believe About Memory? Implications for the Science and Pseudoscience of Clinical Practice. Canadian journal of psychiatry. Revue canadienne de psychiatrie, v. 60, n. 12, p. 541-547, 2015.p. 543.

5 DE AQUINO, José Carlos G. Xavier. A prova testemunhal no processo penal brasileiro. São Paulo: Saraiva, 1987. p. 34.

${ }^{6}$ Cf.: MARQUES, Mateus. Algumas inquietações sobre as contribuições da neurociência em relação aos fins do direito penal. Revista Síntese de direito penal e processual penal, v. 15, n. 92, p. 108-139, jun.-jul. 2015. p. 115. E ainda: JONES, Owen D. et al. Law and neuroscience: recommendations submitted to the President's Bioethics Commission. Journal of Law and the Biosciences, p. 224-236, march 31 ${ }^{\text {st }}$, 2014. p. 226. ${ }^{7}$ Há estudo empírico que demonstra que, após participar de um único curso de psicologia forense, as crenças equivocadas acerca da memória humana e técnicas de interrogatório, entre outros itens, tiveram uma queda de $11 \%$, resultado promissor e que demonstra a eficácia das iniciativas de informação e formação. Cf.: SHAW, Julia. WOODWORTH, Michael. Are the misinformed more punitive? Beliefs and misconceptions in forensic psychology. Psychology, Crime \& Law, p. 1-20, 2013.
} 
Um grande salto foi dado dos anos 1990 até o presente, sobretudo na denominada "década do cérebro"8, que ocupou os anos 1990-1999.

Com a nova perspectiva das neuroimagens, em 1962, Thomas Khun afirmou em sua obra $^{9}$ haver uma crise do paradigma da neurociência. Com o acúmulo de conhecimento, o modelo passa a não ser suficiente para explicar as dúvidas que surgem (denominadas por ele de anomalias), e este acúmulo de anomalias gera a crise do paradigma, a qual ainda vivemos.

O grande desafio encontrado, assim, era (e é) explicar, a partir das detalhadíssimas imagens que podem ser obtidas por meio de exames, os mecanismos fisiológicos que dão origem à percepção, à memória, à atenção, e que são ingredientes ou facetas daquilo a que chamamos consciência. ${ }^{10}$

Há, hoje, técnicas de ressonância magnética funcional (fMRI) na qual é possível visualizar o organismo - e no caso, o cérebro - em operação, em oposição à ressonância magnética tradicional que apenas gera imagens estáticas. Técnica similar, no quesito da identificação de ativação cerebral, é a da tomografia por emissão de pósitrons (PET).

Com a fMRI é possível verificar a ativação de determinados locus cerebrais pelo maior ou menor consumo de oxigênio no tecido - e, com isso, cientistas já tentaram realizar testes para identificar se há diferenças na atividade cerebral do indivíduo que mente e daquele que fala a verdade. ${ }^{11}$

Outra é a técnica chamada de $\mathrm{CKA}^{12}$, avaliação informatizada do conhecimento, a qual mede oscilações na intensidade de ondas cerebrais, as quais ligar-se-iam à familiaridade de

\footnotetext{
${ }^{8}$ GOLDSTEIN, M. Decade of the brain. An agenda for the nineties. West J Med, v. 161, n. 3, p. 239-241, 1994.

${ }^{9}$ KUHN, Thomas S. A estrutura das revoluções científicas. São Paulo: Perspectiva, 1975.

${ }^{10}$ Ibidem. p. 40.

${ }^{11}$ WESTERLINDH, Carlos Prat. Nuevos detectores de mentiras y derecho penal. La Ley Penal - Revista de Derecho Penal, Procesal y Penitenciario, n. 84, p. 30-36, jul.-ago. 2011. p. 32-33. Michele Taruffo chega a concluir que este método seria o "detector de mentiras" ideal, cf.: TARUFFO, Michele. Proceso y neurociencia. Aspectos generales. In: TARUFFO, Michele; FENOLL, Jordi Nieva (Orgs.). Neurociencia y processo judicial. Madrid: Marcial Pons, 2013, p. 16-17.

${ }^{12}$ Computerized Knowlege Assessment.
} 
um indivíduo a certo estímulo - por exemplo a uma pessoa, servindo assim como supedâneo de uma identificação. ${ }^{13}$

Por fim, há técnicas não invasivas de neurocomputação que permitem identificar micro alterações faciais relacionadas a padrões de relatos de mentiras ou verdades. ${ }^{14}$

São técnicas de mapeamento, cerebral e neurofacial, que poderão, em relação aos réus, "repercutir na sua eventual absolvição ou na comprovação de sua responsabilidade penal", o mesmo valendo para o peso a ser dado às declarações de vítimas e de testemunhas servindo de base não apenas a eventual condenação ou absolvição, como também a um possível procedimento por falso testemunho ou denunciação caluniosa. ${ }^{15}$

É necessário cautela, contudo, pois no atual estado da ciência a verdade é que, embora já existam empresas comercializando "detectores de mentira" baseados em fMRI, a ativação de determinadas áreas cerebrais, em si e por si só, não dá qualquer tipo de certeza - mesmo porque, por exemplo, um indivíduo que possua falsas memórias, ao relatá-las, não ativará as áreas cerebrais da mentira, já que acredita estar falando a verdade. ${ }^{16}$

Inobstante o potencial transformativo e sua inexorável inclusão no cotidiano forense, é necessário atentar-se à sedução destas explicações e conclusões neurocientíficas ${ }^{17}$, aplicando sobre elas considerações éticas sobre os limites da neurociência e dos exames de neuroimagem, já que é certo que, no presente estado da ciência, nenhuma das ferramentas existentes permite de fato detectar mentiras ou tentativas de dissimulação.

Tudo o que se percebem são mudanças fisiológicas de fluxo sanguíneo em determinadas regiões cerebrais, regiões essas que em determinados estudos, limitados e direcionados,

\footnotetext{
${ }^{13}$ WESTERLINDH, Carlos Prat. Nuevos detectores de mentiras y derecho penal. La Ley Penal - Revista de Derecho Penal, Procesal y Penitenciario, n. 84, p. 30-36, jul.-ago. 2011. p. 32-33.

${ }^{14}$ Ibidem.

15 RASSI, João Daniel. Neurociência e prova no processo penal: Admissibilidade e valoração. Tese (Doutorado). Faculdade de Direito da Universidade de São Paulo. São Paulo, 2017. p. 21.

${ }^{16}$ THE ROYAL SOCIETY. Neuroscience and the Law. Brainwaves, v. 4, dec. 2011. p. 25-26.

17 Cf. verificado em estudo: WEISBERG, Deena Skolnic et al. The seductive allure of neuroscience explanations. Journal of Cognitive Neuroscience, v. 20, 2008, p. 470. Disponível em: https://www.ncbi.nlm.nih.gov/pmc/articles/PMC2778755/. Acessado em: 08 de janeiro de 2019.
} 
parecem corresponder às hipóteses em questão, não podendo, porém, estes resultados serem extrapolados para uma aplicação ampla ${ }^{18}$.

A respeito das novidades científicas, e a necessária cautela com a qual devem ser tratadas, tem-se a crítica de Hassemer, segundo o qual deve haver indispensável distanciamento e ceticismo dos penalistas para com estas novidades, posto que estes não participam das idas e vindas das ciências neurológicas, vindo a saber, apenas ocasionalmente, de alguns resultados descontextualizados. ${ }^{19}$

Assim, diferente do que se identifica, por exemplo, entre sociólogos e penalistas, entre os quais é possível ocorrer uma "acomodação e integração de fragmentos sistêmicos, ou seja, ambas as ciências lado a lado", o autor entende que até mesmo o próprio diálogo com as ciências neurológicas seria impossível, devendo ser portanto rechaçado. ${ }^{20}$

Esta contundente crítica é válida e pertinente, principalmente ao se ter em mente o fato de que o convencimento acerca dos potenciais da ciência e de seus métodos não necessariamente deriva de uma compreensão real e precisa das implicações e limitações das técnicas de neurociência cognitiva, mas da falta de conhecimentos específicos para se receber e entender tais dados de forma crítica. Além disso, a compreensível satisfação que as promessas contidas em tais estudos causam ao leigo certamente tornam mais fácil sua aceitação. $^{21}$

Ademais, é necessário combater o reducionismo neurológico - a ideia de que os indivíduos e suas atitudes nada mais seriam do que estados neurais -, evitando colocar as técnicas de monitoração neurológica em um pedestal que estas não apenas não podem como não devem ocupar. ${ }^{22}$

\footnotetext{
${ }^{18}$ FORD, Elizabeth. AGGARWAL, Neil. Neuroethics of Functional Neuroimaging in the Courtroom. In: SIMPSON, Joseph R. (Ed.). Neuroimaging in Forensic Psychiatry: From the Clinic to the Courtroom. New Jersey: John Wiley \& Sons, p. 325-340, 2012. p. 327.

${ }^{19}$ HASSEMER, Winfried. Neurociência e culpabilidade em Direito Penal. Revista Brasileira de Ciências Criminais, vol. 100, São Paulo: Ed. RT, 2013. p. 215.

${ }^{20}$ Ibidem.

21 RASSI, João Daniel. Neurociência e prova no processo penal: Admissibilidade e valoração. Tese (Doutorado). Faculdade de Direito da Universidade de São Paulo. São Paulo, 2017. p. 89.

${ }^{22}$ PARDO, Michael S. PATTERSON, Dennis. Minds, Brains, and Law. The conceptual Foundations of Law and Neuroscience. Nova Iorque: Oxford University Press, 2013. p. 26.
} 
Contudo, acreditamos que o diálogo entre as ciências já existe, ainda que de forma primária, e trata-se de tendência já irreversível, de modo que se faz imperativo balizar a utilização dos conhecimentos das searas alheias ao Direito, como a neurociência, a partir da difusão de conhecimentos sobre as limitações dos métodos e sobre as bases sobre as quais estes trabalham, capacitando os penalistas para a compreensão do tema e possibilitando aplicação criteriosa.

Trazendo a questão à concretude do Poder Judiciário, uma observação interessante da pesquisa empírica realizada é que a quase totalidade dos acórdãos que tratam da desnecessidade de perfeita coincidência entre as narrativas e a impossibilidade de exigência de riqueza de detalhes de testemunhos sobre fatos ocorridos há certo tempo é pela manutenção da condenação, enquanto aqueles que referem-se ao reconhecimento pessoal e as suas limitações são pela absolvição - inclusive os acórdãos que tratam do testemunho infantil e o voto vencido que trata da captação sensorial de detalhes.

Também se notou que a quase totalidade dos acórdãos que tratam da fragilidade do reconhecimento pessoal originam-se do Tribunal de Alçada Criminal de São Paulo, extinto em 2004, parecendo ter havido uma mudança no posicionamento da maioria das decisões quanto ao tema da memória, passando este a focar na impossibilidade de exigir muitos detalhes e a coerência completa dos testemunhos, mudança esta que pode ser vista como um enfoque mais punitivista do órgão judicial em detrimento de prestigiar a presunção de inocência.

Embora decisões acerca da produção probatória não sejam o foco desta tese, é interessante notar que, quando se trata do tema de busca da verdade real, as Cortes encontram-se melhor alinhadas com o conceito das fragilidades da memória humana. Curiosamente, o mesmo não possa ser dito quanto à análise desta mesma memória no tocante ao seu (des)valor probatório.

Isso é interessante posto que um processo penal comprometido com a busca da verdade (ainda que a verdade do processo) "deveria contar com regras que expressassem o objetivo de redução de erros; isto é, deveria se preocupar em reduzir os riscos de condenar 
inocentes e de absolver culpados", adotando "procedimentos probatórios formulados a partir de metodologias com maior potencial veritativo". ${ }^{23}$ Acontece que:

\begin{abstract}
“A partir de uma perspectiva moral ou política [...] Um standard de prova penal mais elevado serve ao objetivo de reduzir a condenação de inocentes porque dificulta as condenações em geral. Em todos os processos, exige-se mais da hipótese acusatória para que seja considerada verdadeira. Como consequência direta da maior dificuldade imposta à hipótese condenatória, a ocorrência de absolvições de culpados seria facilitada. Evita-se a produção de uma classe de erro a partir da facilitação do erro considerado "menos pior". Por outro lado, caso se optasse por um standard de prova menos elevado (por exemplo aquele conhecido como "probabilidade prevalecente"), isso expressaria a compreensão de que condenações injustas e absolvições injustas são erros da mesma ordem de importância, não havendo algum cuja eliminação devesse ser preferida. O compromisso de se evitar as condenações de inocentes e o compromisso de se evitar a absolvição de culpados seriam da mesma intensidade. Ora, se não enxergamos como pior a condenação de inocentes, não há porque fixar a exigência de prova da hipótese acusatória em patamares especialmente mais altos." ${ }^{24}$
\end{abstract}

Infelizmente "o sistema legal é resistente a mudanças, em especial quando elas são fundamentais, mas inconvenientes" 25 . Leonard Mlodinow traz passagem bastante mendaz que bem reflete o comportamento do Poder Judiciário e a grande parte de seus operadores quando se questionam e apontam as falhas do sistema.

"[...] um católico, um judeu - os dois brancos - e um negro, todos mortos e se aproximando dos portões do céu. O católico diz: "Eu fui um homem bom a vida toda, mas sofri um bocado de discriminação. O que devo fazer para ir para o céu?'

'Essa é fácil', responde Deus. 'Para entrar no céu você só precisa soletrar uma palavra.'

'Que palavra?', pergunta o católico.

'Deus', responde o Senhor.

O católico soletra D-E-U-S e entra no céu. Então o judeu se aproxima. Ele também diz: 'Eu fui um homem bom.' E acrescenta: 'E não foi fácil, pois tive de lidar com discriminação a vida toda. O que devo fazer para entrar no céu?'

Deus responde: 'Essa é fácil. Você só precisa soletrar uma palavra.'

'Qual palavra?', pergunta o judeu.

'Deus', responde o Senhor.

${ }^{23}$ MATILDA, Janaina. Standards de prova: a modéstia necessária a juízes na decisão sobre os fatos. Disponível

em: https://www.academia.edu/37511922/Matida_2018_Standards_de_prova_a_mod\%C3\%A9stia_necess\%C3\% A1ria_a_ju\%C3\%ADzes_na_decis\%C3\%A3o_sobre_os_fatos.pdf. Acessado em: 05.04.2019.p. 9.

${ }^{24}$ Ibidem.

${ }^{25}$ MLODINOW, Leonard. Subliminar - como o inconsciente influencia nossas vidas. Rio de Janeiro: Zahar, 2018. p. 76. 
O judeu diz D-E-U-S e também entra no céu. Depois o negro se aproxima e diz que foi legal com todo mundo, mesmo tendo enfrentado muita discriminação por causa da cor da pele.

Deus diz: 'Não se preocupe, aqui não existe discriminação.'

'Obrigado', diz o negro. 'Então como eu faço para entrar no céu?'

'Essa é fácil', responde Deus. 'Você só precisa soletrar uma palavra!'

'Qual palavra?', pergunta o negro.

'Tchecoslováquia', responde o Senhor." 26

A nosso ver, a ciência da memória é (ou deve ser) tão central ao Direito quando a biologia o é para a medicina. ${ }^{27}$ Este trabalho busca, então, aproximar a questão aos operadores do Direito de forma que estes o consigam entender de modo mais palatável do que a tentativa de soletrar Tchecoslováquia.

Vejamos então, com mais detalhes, a memória humana e suas particularidades, e a interface desta para com o Direito Penal.

${ }^{26}$ Ibidem. p. 282-283.

${ }^{27}$ BRAINERD, C. J. Murder must memorize. Memory, v. 21, p. 547-555, 2013. p. 547. 


\section{MÉTODO}

A presente tese utilizou diferentes métodos técnico-científicos em sua elaboração, com predominância do método dialético, através da análise qualitativa de trabalhos no campo do Direito, da Medicina, e da Psicologia Cognitiva, com a utilização dos entendimentos mais recentes e de relevância científica.

Utilizaram-se parâmetros nacionais e internacionais sobre o tema, servindo-se esta tese, assim, à aplicação concreta em quaisquer ordenamentos jurídicos, dado o fato de não apoiar-se em constrições derivadas das regras específicas de direito processual ou material, mas valer-se de achados que se aplicam de forma geral aos seres humanos, mais especificamente em situações nas quais são testemunhas de fatos e prestam depoimentos a respeito de suas recordações.

Alguns trabalhos serviram de relevante base teórica para a pesquisa, sobre a qual se ergueu a tese, sendo estes as obras Ivan Antonio Izquierdo, Antonio Damásio, Dean Buonomano, Elizabeth Loftus, Daniel Schacter, Stephen Ceci e Maggie Bruck, Gisli Gudjonsson, Matthew Fanetti, Eric Kandel, e Roberto Lent.

A seleção dos trabalhos a serem analisados deu-se através de pesquisa por textos que tratassem das temáticas de memória humana, prova testemunhal e testemunho, psicologia e/ou psiquiatria forense, e neurociências, nas seguintes bases de dados, nacionais e internacionais: Sistema Dedalus (base de dados bibliográficos da USP), HeinOnline, JSTOR, Wiley Online Library, Elsevier, Biblioteca do Instituto Brasileiro de Ciências Criminais, e PubMed, selecionando-se as obras de forma qualitativa e conforme a adequação ao tema, sem corte temporal.

Realizou-se pesquisa cruzada de referências em trabalhos recentes sobre o tema e defendidos junto à Universidade de São Paulo, sendo de relevâncias as Teses de Doutorado de João Daniel Rassi, a respeito de neurociência e sua admissão como meio de coleta e interpretação de provas no processo penal, e Mariângela Tomé Lopes, sobre os 
mecanismos envolvidos com o reconhecimento pessoal e sugestões de melhores práticas para este procedimento.

Verificou-se a existência de pesquisa empírica datada de 2015 e realizada por encomenda do Ministério da Justiça com entrevistas acerca da percepção de atores judiciais e operadores do Direito acerca do valor da prova testemunhal e suas formas de obtenção, tendo-se identificado que para estes a prova testemunhal apresenta supremacia bastante relevante.

Por fim, foi feita pesquisa de jurisprudência no Supremo Tribunal Federal, no Superior Tribunal de Justiça, e no Tribunal de Justiça do Estado de São Paulo ${ }^{28}$ de modo a se verificar no caso concreto qual é o entendimento adotado acerca do tema. Esta pesquisa jurisprudencial foi feita mediante a inserção das seguintes palavras-chave nas ferramentas de busca de cada Tribunal: "falibilidade da memória"; "neurociência"; memória E humana.

A posterior análise qualitativa foi realizada mediante o exame da íntegra das decisões quando o saldo das buscas resultou em até 100 achados $^{29}$. Para achados em valores superiores, realizou-se a análise qualitativa sobre resultados selecionados mediante a aplicação de filtros amostrais de relevância (mais relevante) e temporalidade (mais recente e mais antigo $)^{30}$, de modo a se verificar o estabelecimento e a evolução dos posicionamentos adotados.

Das decisões contendo a palavra-chave "neurociência" no Tribunal de Justiça do Estado de São Paulo, no Superior Tribunal de Justiça, e no Supremo Tribunal Federal, chegou-se a um total de 94 acórdãos no Tribunal Paulista, oito decisões monocráticas e um acórdão no STJ, e apenas uma decisão monocrática no STF. São números que constituem fração ínfima frente ao total de casos existentes, demonstrando a aridez que cerca o assunto na seara judicial.

\footnotetext{
${ }^{28}$ Escolhido tanto pela base geográfica desta Universidade, como por ser o maior tribunal estadual brasileiro.

${ }^{29}$ Valor de corte estabelecido de modo a permitir tanto uma base concreta de análise quantitativa, quanto a exequibilidade de análise da íntegra das decisões.

${ }^{30}$ Utilizou-se dos filtros existentes no próprio sistema de busca dos tribunais, com ordenação por relevância e por data de registro.
} 
Na divisão destas decisões por assuntos, encontramos que, nas Cortes Superiores, apenas duas das decisões tratam realmente de questão neurocientífica: a primeira mencionando as influências das emoções sobre a tomada de decisão individual, em ação que discutia a inserção de imagens com alertas nos maços de cigarro $^{31}$, e a segunda considerando que a pedofilia é uma psicopatia e, por isso, justifica-se a prisão preventiva daquele réu ${ }^{32}$.

Já na seara estadual os assuntos foram mais variados, com 26 acórdãos envolvendo questões médicas - como alterações da atenção em acidentes, doenças ocupacionais, planos de saúde, tratamentos e materiais, diagnósticos e erros -, 18 acórdãos tratando de temas diversos e apenas tangencialmente ligados à palavra chave, um caso tratando da matricula de crianças pelo mês de nascimento e seu desenvolvimento cognitivo, e um caso tratando da existência de consciência animal, em discussão no âmbito de liberdade de culto e sacrifício de animais.

Especificamente no Direito Penal, foco de interesse do estudo, há um acórdão que considera a validade e legitimidade das avaliações psicossociais para decisões sobre progressão de regime prisional, um acórdão que trata do testemunho infantil e a possibilidade de influência de adultos sobre este $^{33}$, um voto vencido em acórdão que trata do reconhecimento pessoal com análise da captação sensorial de detalhes ${ }^{34}$, 18 acórdãos que tratam da fixação de detalhes na memória ao longo do tempo ${ }^{35}$, cinco acórdãos que tratam da fixação dos detalhes e trazem como conclusão a desnecessidade de identidade perfeita entre depoimentos colhidos em momentos diversos (sobretudo em casos envolvendo o testemunho de agentes policiais $)^{36}$-, e por fim 23 acórdãos que lidam com o reconhecimento pessoal, trabalhando a insegurança advinda deste tipo de prova e a possibilidade de indução de um reconhecimento ${ }^{37}$.

\footnotetext{
${ }^{31}$ Recurso Especial 1.261.002.

${ }^{32}$ Habeas Corpus 9294-5.

33 Apelação n. 9187935-94.2004.8.26.0000.

${ }^{34}$ Apelação n. 0045692-04.2008.8.26.0564. Similarmente há acórdão civil que trata da fixação de detalhes visuais com estímulos como cores chamativas: Apelação n. 0104465-42.2009.8.26.0003.

${ }^{35}$ Autos n. 0060291-64.2010.8.26.0050; 0044329-41.2010.8.26.0554 0064082-07.2011.8.26.0050; 001786358.2010.8.26.0344；0095632-54.2010.8.26.0050；0088055-5.2010.8.26.0050；0016436-47.2009.8.26.0510; 0002995-75.2010.8.26.0344; 0002561-06.2012.8.26.0445; 0078755-34.2013.8.26.0050 (Apelação e Embargos de Declaração); 0049832-05.2010.8.26.0405; e 1.095.015.3/1.

36 Autos n. 3011587-19.2013.8.26.0161; 0002794-95.2012.8.26.0091; 0079043-69.2012.8.26.0000; 1105.395.3/0; e 9022834-05.2014.8.26.0000.

37 Autos n. 0003617-14.2015.8.26.0415; 490.689.3/4; 429.247.3/6; 993.07.118/182-0; 442.937.3/0; 914.117.3/4; 993.06.115601-6; 993.06.018537-3; 993.07.070466-7; 966.037.3/4; 1.088.543.3/4; 1377917/5;
} 
Feito, ainda, levantamento nos mesmos Tribunais já mencionados com as palavras-chave memória E humana e "falibilidade da memória", a pesquisa gerou a quase totalidade de resultados ligados a requerimentos de produção antecipada de provas em virtude do decurso temporal, e a permissão ou não desta pelos magistrados, com a maioria absoluta das decisões autorizando a antecipação.

Neste segundo levantamento foram encontradas oito decisões no Supremo Tribunal Federal $^{38}$, sendo a mais antiga do ano de 2008 - demonstrando o quão recente são tais discussões no âmbito judicial -, na qual há o entendimento de que a urgência na produção antecipada de prova não se justificaria quando fundada "apenas na possibilidade de esquecimento em virtude do tempo",39.

Em sentido contrário a decisão mais recente, datada de fevereiro de 2019, autoriza a antecipação probatória, afirmando que "o longo período transcorrido entre os fatos e colheita das provas (quase dez anos) pode fazer com que sejam perdidas informações relevantes ao deslinde da causa" ${ }^{\natural 0}$. Esta decisão segue a corrente que se estabeleceu como majoritária na Corte, com a única exceção encontrada na supracitada decisão do ano de 2008.

No Superior Tribunal de Justiça foram encontrados 37 acórdãos e 496 decisões monocráticas $^{41}$ com a pesquisa memória $E$ humana, e 27 acórdãos e 81 decisões monocráticas com a pesquisa "falibilidade da memória", sendo que o segundo conjunto insere-se no primeiro com a exceção de um acórdão ${ }^{42}$ - totalizando, assim, 38 acórdãos.

$1427147 / 3 ; \quad 1430731 / 5 ; \quad 1409597 / 0 ; \quad 1385153-6 ; \quad 1349011 / 4 ; \quad 14333211 / 0 ; \quad 1435589 / 9 ; \quad 1376027 / 1 ;$ 1.376.027/1; 0003008-93.2004.8.26.0050; e 0062090-45.2010.8.26.0050 (voto vencido).

${ }^{38}$ Junto ao SUPREMO TRIBUNAL FEDERAL houve diferenciação nos resultados encontrados entre os termos chave pesquisados, estando a pesquisa 'falibilidade da memória' contida nos resultados da busca 'memória E humana'. São os resultados: Habeas Corpus n. 110.280; 138.810; 147.521; 109.728; 128.375; 124.244/MC; $114.519 / \mathrm{MC}$; e 93.710.

${ }^{39}$ Habeas Corpus 93.710.

${ }^{40}$ Habeas Corpus 138.810

${ }^{41}$ Estas não foram analisadas, sendo observado em visualização superficial que se referiam também ao tema da produção probatória.

${ }^{42}$ Habeas Corpus 339.460 
O único acórdão da "falibilidade da memória" que não se insere no primeiro espaço amostral $^{43}$ traz o entendimento de que se legitima a antecipação da produção probatória pelo risco de perecimento da prova testemunhal em razão da probabilidade do esquecimento.

Acrescendo a estes 38 acórdãos, verificou-se a existência de dez precedentes relacionados ao tema, mencionados no bojo dos votos e não identificados nas buscas ${ }^{44}$, chegando-se a um total de 48 decisões colegiadas. Da análise destas, extraíram-se aquelas que não guardavam relação com a questão, totalizando assim um espaço amostral de 41 acórdãos.

O caso mais recente, datado de dezembro de $2018^{45}$, segue corrente absolutamente majoritária na Corte pela concessão da antecipação probatória ${ }^{46}$, corrente inaugurada no ano de $1997^{47}$ - foram encontradas apenas oito decisões que negam esta possibilidade ${ }^{48}$, todas sob o fundamento de que o mero decurso do tempo não seria razão suficiente para autorizar a excepcionalidade da colheita antecipada.

Por fim, no âmbito do Tribunal de Justiça do Estado de São Paulo, a pesquisa memória E humana trouxe 4.375 acórdãos, enquanto a pesquisa "falibilidade da memória" trouxe 299 resultados. $^{49}$

$\mathrm{O}$ acórdão mais relevante a tratar de memória $\mathrm{E}$ humana aduz que a simples limitação da memória humana não seria razão idônea para a antecipação probatória, afirmando ainda que os elementos trazidos do inquérito policial serviriam a fazer uma preservação da memória inicial ${ }^{50}$, enquanto o caso mais recente deferia a antecipação requerida, pois o

\footnotetext{
${ }^{43}$ Ibidem.

${ }^{44}$ HC 310.214; RHC 74.083; RHC 21.519; HC 97.452; HC 67.672; RHC 6.220; REsp 249.476; ROMS 142.283; HC 20.233; e HC 25.518.

${ }^{45}$ Recurso em Habeas Corpus 97.930.

${ }^{46}$ RHC 97.930; RHC 97.539; RHC 83.672; RHC 56.791; RHC 66.668; RHC 57.342; HC 435.948; HC 169.125; AgRg no AREsp 829.492; AgRg no HC 416.166; AgRg no AREsp 911.296; RHC 65.207; RHC 54.563; HC 309.330; RHC 54.509; HC 239.269; HC 239.290; HC 210.388; HC 203.896; HC 186.053; HC 168.677; HC 153.668; RHC 54.561; HC 118.459; RHC 16.604; HC 339.460; HC 310.214; RHC 74.083; RHC 6.220; REsp 249.476; ROMS 142.283; HC 20.233; e HC 25.518.

${ }^{47}$ Recurso em Habeas Corpus 6.220.

${ }^{48}$ RHC 68.747 - havendo voto vencido pela possibilidade; RHC 51.861 - igualmente havendo voto vencido pela possibilidade; Rcl 3.448; HC 122.936; HC 45.873; RHC 21.519; HC 97.452; e HC 67.672.

${ }^{49}$ Dado o volume, utilizaram-se os filtros de pesquisa para seleção por relevância e data de registro. Notouse, ainda que em análise perfunctória, que a quase totalidade dos resultados trazidos tratava também da questão relacionada à possibilidade de produção antecipada de provas.

${ }^{50}$ RESE n. 0001083-39.2008.8.26.0562, Relator Desembargador Augusto de Siqueira, j. 19.09.2013.
} 
decurso do tempo "certamente acarretará o esquecimento de detalhes importantes dos fatos" $" 51$.

Por sua vez, o caso mais antigo trata do fenômeno da chamada transferência inconsciente ${ }^{52}$, trazendo a noção de que a testemunha "pode ser induzida a identificar um rosto que lhe pareça familiar, quando já vira alguém semelhante, podendo tomá-lo como o provável autor do crime".

Já com relação à pesquisa "falibilidade da memória", o acórdão mais relevante trata do cabimento da antecipação probatória sob o fundamento de que esta "pode perder-se face à falibilidade da memória das testemunhas" ${ }^{, 53}$, assim como o mais recente (sendo este o mesmo já citado na busca anterior) ${ }^{54}$, e o mais antigo ${ }^{55}$.

Estas foram, assim, as bases metodológicas e os parâmetros empíricos utilizados para a elaboração da presente tese.

\footnotetext{
${ }^{51}$ RESE n. 0012916-96.2014.8.26.0577, Relator Desembargador Sérgio Coelho, j. 20.02.2019.

52 Apelação n. 0006706-75.2003.8.26.0266, Relator Desembargador Figueiredo Gonçalves, j. 18.07.2006.

${ }^{53}$ RESE n. 0049037-60.2013.8.26.0577, Relator Desembargador Damião Cogan, j. 27.11.2014.

${ }^{54}$ RESE n. 0012916-96.2014.8.26.0577, Relator Desembargador Sérgio Coelho, j. 20.02.2019.

${ }^{55}$ MS n. 0062516-76.2011.8.26.0000, Relator Desembargador David Haddad, j. 30.06.2011.
} 


\section{CONCLUSÃO}

Ao longo desta tese realizou-se uma análise dos fundamentos neurocientíficos e psicológicos que cercam a memória humana, sintetizando-se seu funcionamento e falhas inerentes, bem como apontando o desenvolvimento dos métodos considerados mais seguros e adequados para a produção da prova testemunhal, conjugando as diferentes ciências para oferecer à academia e à sociedade um material que se mostre apto a orientar estudos e políticas que tratem do tema, seja no que tange a aprimorar produção probatória, seja no tocante a dar às provas testemunhais a devida valoração.

Não foram perdidas de vista as implicações éticas do trabalho, ao passo em que ao se fornecer informações a respeito de características que estatisticamente preveem uma maior ou menor confiabilidade da memória individual, pode-se estimular uma classificação informal de sujeitos que passem a ter seus relatos levados em maior ou menor consideração sem qualquer adequação individual e concreta, bem como de que o maior conhecimento acerca da questão possa levar à deturpação de relatos e memórias por atuações propostas.

Contudo, considerando-se o amplo interesse da questão, acredita-se que sua aplicação positiva suplante quaisquer eventuais - e pouco práticas - aplicações perniciosas, haja vista principalmente a quase total ausência de abordagem da questão e, no meio forense, a patente falta de preparo das Cortes sobre o tema.

Entende-se que, dadas as particularidades do país, com amplas diferenças de recursos orçamentários da Polícia Judiciária e do Poder Judiciário dos estados, bem como a sobrecarga do sistema de Justiça criminal, e indo além da determinação legal de existência de núcleo especializado na aplicação do 'depoimento especial'/'depoimento sem dano' aos menores vítimas de violência, é necessário o treinamento e implementação de formas de entrevista forense que tragam melhoria da qualidade dos resultados investigativos também para a colheita de testemunhas de adultos. 
Os protocolos e parâmetros do 'depoimento especial' não levam em conta detalhes para além do limiar da psicologia, pautando-se no (necessário) acolhimento do menor, porém sem ir além com técnicas de melhor recuperação e redução de contaminações.

No tocante aos adultos, a situação é completamente abandonada, não havendo qualquer capacitação, ou mesmo preocupação, para com a preservação de memórias e obtenção de relatos fidedignos, apenas focando-se na obtenção do maior número possível de resultados (julgamentos), independentemente de sua correspondência com os fatos e da real justiça decisória.

Para além da escolha de métodos de questionamento e entrevista, um ponto que restou claramente identificado é o de que quando se trata da aventada "busca da verdade real", as decisões encontram-se melhor alinhadas com o conceito das fragilidades da memória humana, o mesmo não podendo ser dito quanto à análise destas mesmas fragilidades no tocante ao valor a ser atribuído à prova eventualmente produzida, o que parece revelar tanto uma falta de conhecimento quanto um possível viés do julgador a descartar como mero inconformismo defensivo (depreciativamente chamado de jus sperniandi) ${ }^{332}$ os argumentos que trabalhem nesta linha.

Desse modo, entende-se que os conhecimentos ora trazidos a lume não apenas são necessários como medida de atualização da ciência criminal junto dos conhecimentos científicos mais recentes, como também do ponto de vista de armar os operadores do Direito para buscarem e garantirem a preservação da presunção de inocência e da ampla defesa, princípios caros ao Direito Penal e hodiernamente tripudiados, não se podendo permitir passivamente que sua profanação se dê mediante a ignorância dos temas ora tratados ou, pior, com sua má-utilização.

Para responder à pergunta com a qual se começou esta tese (estaria a atual concepção do Direito Penal acerca da confiabilidade da prova testemunhal - e, portanto, da memória condizente com a realidade da mente humana, e haveria modos de obtenção de relatos com a maior fidedignidade possível?) podemos dizer com clareza que o Direito Penal brasileiro

${ }^{332}$ Referência de fato realizada pelo Desembargador Fernando Matallo, do Tribunal de Justiça do Estado de São Paulo, no julgamento da Apelação n. 990.09.161889-6 em 22.10.2009, caso no qual a defesa argumentou pela possibilidade de "falsa associação entre a figura do assaltante e do apelante", o que foi visto pelo julgador como "jus sperniandi do douto defensor". 
não se encontra atualizado frente aos conhecimentos necessários à colheita, produção, e valoração da prova testemunhal da forma mais justa e precisa possível, havendo a urgente necessidade de capacitação dos atores jurídicos e de criação de protocolos obrigatórios para balizar sua atuação.

Sugere-se para tal a necessária atualização de estudantes, operadores do Direito, membros do Poder Judiciário, e das Polícias a respeito do atual conhecimento neurocientífico no tocante à memória humana e suas limitações, bem como a criação de protocolos de colheita dos depoimentos testemunhais e de verificação dos resultados concretos destas coletas e das variáveis envolvidas nos depoimentos colhidos, criando parâmetros que humanizem e deem maior qualidade às colheitas probatórias - levando, em consequência, a uma melhor qualidade das investigações - , bem como parâmetros que balizem a decisão do ponto de vista da análise científica daquela prova, com a preservação do in dubio pro reo.

Não se trata de tentativa de separar a verdade real de outras narrativas, mas de capacitar todos os atores envolvidos na atuação do pesado braço do Estado para uma aplicação humana de suas punições, de forma que reconheçam as dúvidas inerentes ao sistema e possam sopesá-las no caso concreto para chegar a decisões que não fechem os olhos a estes elementos em favor de condenações indiscriminadas.

O resultado buscado não é um menor número de condenações, embora se acredite que na atual situação, em que se prende muito e prende-se mal, esta será uma consequência inevitável. Busca-se, isso sim, uma maior qualidade decisória, com melhores juízos de certeza em linha com o adequado funcionamento do sistema criminal em um Estado Democrático de Direito.

Propõe-se assim que se determine como política institucional do Poder Judiciário a adoção dos métodos da Entrevista Cognitiva e a capacitação de seus integrantes, com atenção tanto às bases psicológicas da questão - que se ligam sobretudo à forma de questionamento e de não-contaminação -, como com as bases neurológicas da memória - possibilitando um melhor entendimento da formação da memória a nível individual, a depender das características fisiológicas daquele que é entrevistado, bem como de quais aspectos devem 
ter maior atenção do entrevistador por sua importância na modulação da percepção, da codificação, ou da evocação.

Ligando-nos ao segundo questionamento de abertura desta tese ("há formas de se robustecer a ciência jurídica no tocante a estudos como o presente, e à sua aplicação prática?"), entende-se ser imperativo que a Medicina Forense retome seu papel de protagonismo junto ao Direito Penal, auxiliando os órgãos da Polícia Judiciária e do Poder Judiciário na colheita de provas e na valoração destas para a tomada de decisões, trazendo a ciência penal e seus resultados concretos para junto da ciência atual.

Para tanto, propõe-se como necessário um fortalecimento desta desde a base de formação dos operadores do Direito, com a (re)inserção de matérias de Medicina Forense nos currículos acadêmicos e a adoção de políticas institucionais de estímulo à produção científica da área, formando uma nova base de operadores capacitados para a tarefa de integração de ambas as ciências no ainda rígido contexto jurídico.

Tal trabalho de base também deve ser acompanhado pela imperativa capacitação dos integrantes da Polícia Judiciária, do Ministério Público, e da Magistratura, não apenas na utilização dos métodos, conforme já descrito, mas para a compreensão do tema, ainda que não de forma profunda, sobretudo as implicações das limitações e falhas de memória para a aplicação concreta da Justiça, evitando a já constatada e preocupante supervalorização dos testemunhos e depoimentos em detrimento de outras fontes de prova, e os erros e injustiças daí derivados.

Finalmente, espera-se que trabalhos futuros possam apoiar-se nesta tese, desenvolvendo de forma prática, inclusive em estudos ligados ao processo penal, os melhores métodos para a implantação destes conceitos no cotidiano forense, convidando-se assim os pesquisadores da área para contribuir com este desafio. 


\section{BIBLIOGRAFIA}

ALTAVILLA, Enrico. Psicologia giudiziaria. Torino: Torinese, 1955.

ALTMAN, Christopher M. et al. Witness' memory for events and faces under elevated levels of intoxication. Memory, v. 26, n. 7, p. 946-959, 2018.

ÁLVAREZ AYLLÓN, Gloria. VALLADOLID BARINGO, Noelia. El psicólogo forense ante el engano em las declaraciones. Cuadernos de política criminal, n. 85, p. 5-57, 2005.

AMBROSIO, Graziella. Psicologia do Testemunho. Rev. Direito Econ. Socioambiental, Curitiba, v. 1, n. 2, p. 395-407, jul./dez. 2010.

ARCE FERNÁNDEZ, Ramón. FARIÑA RIVERA, Francisca. La evaluación de la credibilidad del testimonio: evaluación cognitiva de la veracidade de testimonios y declaraciones. In: DELGADO BUENO, Santiago. Psiquiatria legal y forense. Barcelona: Bosch, p. 21-46, 2013.

ARLT, Sönke. Non-Alzheimer's disease-related memory impairment and dementia. Dialogues in Clinical Neuroscience, v. 15, n. 4, p. 465-473, 2013.

AVILA, Gustavo Noronha de. Falsas memórias e sistema penal: a prova testemunhal em xeque. Rio de Janeiro: Lumen Juris, 2013.

. BALDASSO, Flaviane. A repercussão do fenômeno das falsas memórias na prova testemunhal: uma análise a partir dos julgados do Tribunal de Justiça do Rio Grande do Sul. Revista Brasileira de Direito Processual Penal, v. 4, n. 1, p. 371-409, jan./abr. 2018.

AZNAR-BLEFARI, Carlos. PADILHA, Maria da Graça. Capacitação para o uso do Protocolo NICHD em profissionais sul-brasileiros. Revista de Psicología, v. 24, n. 1, p. 119, 2015.

BADARÓ, Gustavo. Processo Penal. São Paulo: Elsevier, 2012.

BALLARD, Michael Edward. GALLO, David A., DE WIT, Harriet. Amphetamine Increases Errors During Episodic Memory Retrieval. J Clin Psychopharmacol., v. 34, n. 1, p. 85-92, feb. 2014. 
BISBY, J. A. BURGESS, N. Differential effects of negative emotion on memory for items and associations, and their relationship to intrusive imagery. Current Opinion in Behavioral Sciences, n. 17, p. 124-132, 2017.

BLAGROVE, M. et al. Procedural and declarative memory task performance, and the memory consolidation function of sleep, in recent and abstinent ecstasy/MDMA users. $J$ Psychopharmacol., v. 25, n. 4, p. 465-477, apr. 2011.

BRAINERD, C. J. Murder must memorize. Memory, v. 21, p. 547-555, 2013.

BREGMAN, Norman J. MCALLISTER, Hunter A. Eyewitness Testimony: The role of commitment in increasing reliability. Social Psychology Quarterly, v. 45, n. 3, p. 181-184, sep. 1982.

BRUCK, Maggie et al. "I hardly cried when I got my shot!" Influencing children's reports about a visit to their pediatrician. Child Dev., v. 66, n. 1, p. 193-208, Feb. 1995. Disponível em: http://www.ncbi.nlm.nih.gov/pubmed/7497825. Acessado em: 25.7.2016.

BUONOMANO, Dean. O cérebro imperfeito. Rio de Janeiro: Elsevier, 2011.

CAMPOS, Roberto Augusto de Carvalho. CAMARGO, Rosmari Aparecida Elias. Revisão dos Instrumentos de diagnóstico médico-forense no alcoolismo. Revista da Faculdade de Direito da Universidade de São Paulo, v. 104, p. 379-404, jan.-dez. 2009.

CARIDADE, Sonia. TRINDADE, Jorge. A prova pericial psicológica e o método de análise da credibilidade das declarações (SVA): reflexões: Revista Brasileira de Ciências Criminais, v. 25, n. 136, p. 187-203, out. 2017.

CECI, Stephen J. BRUCK, Maggie. Child witnesses: Translating research into policy. Social Policy Report, v. 7, n. 3, 1993. Disponível em: http://files.eric.ed.gov/fulltext/ED390517.pdf. Acessado em: 25.7.2016.

CIALDINI, Robert B. Armas da persuasão. Rio de Janeiro: Sextante, 2012.

CONWAY, Martin A. LOVEDAY, Catherine. Remembering, imagining, false memories \& personal meanings. Consciousness and Cognition, n. 33, p. 574-581, 2015.

CUNHA, Paulo J et al. Alterações neuropsicológicas em dependentes de cocaína/crack internados: dados preliminares. Rev. Bras. Psiquiatr., v. 26, n. 2, p. 103-106, Jun. 2004. 
Disponível em: http://www.scielo.br/scielo.php?script=sci_arttext\&pid=S151644462004000200007\&lng=en\&nrm=iso. Acessado em: 08.3.2019.

DAMASIO, Antonio R. O Erro de Descartes. São Paulo: Companhia das Letras, 2012.

DAVIES, Graham. HINE, Sarah. Change Blindness and Eyewitness Testimony. The Journal of Psychology, v. 141, n. 4, p. 423-434, 2007. Disponível em: http://psych.unl.edu/mdodd/psy498/cbeyewitness.pdf. Acessado em: 27.3.2018.

SHEPHERD, J.W. ELLIS, H.D. Similarities effects in face recognition. The American Journal of Psychology, v. 92, p. 507-523, 1979.

DAVIES, S. J. et al. Cognitive impairment during pregnancy: a meta-analysis. Med J Aust, v. 208, n. 1, p. 35-40, 15 jan. 2018. Disponível em: https://www.ncbi.nlm.nih.gov/pubmed/29320671. Acessado em: 08.3.2019.

DE AQUINO, José Carlos G. Xavier. A prova testemunhal no processo penal brasileiro. São Paulo: Saraiva, 1987.

DE LORENZI, Dino Roberto Doares et al. Fatores indicadores da sintomatologia climatérica. Rev Bras Ginecol Obstet, v. 27, n. 1, p. 12-19, 2005. Disponível em: http://www.scielo.br/pdf/\%0D/rbgo/v27n1/24286.pdf. Acessado em: 08.3.2019.

DEPARTAMENTO DE FISIOLOGIA E BIOFÍSICA DO INSTITUTO DE CIÊNCIAS BIOMÉDICAS DA UNIVERSIDADE DE SÃO PAULO. Vigília \& Sono. Disponível em: http://fisio2.icb.usp.br:4882/wp-content/uploads/2016/08/PsicologiaAula32017.pdf.

Acessado em: 30.05.2019.

DEVITT, Aleea L. SCHACTER, Daniel L. False memories with age: Neural and cognitive underpinnings. Neuropsychologia, n. 91, p. 346-359, 2016.

DI GESU, Cristina Carla. Prova penal e falsas memórias. Porto Alegre: Livraria do Advogado, 2014.

EAGLEMAN, David. Cérebro: uma biografia. Rio de Janeiro: Rocco, 2017.

FAIGMAN, David L. Judges as “Amateur Scientists”. Boston University Law Review, n. 86, p. 1207-1225, 2006. 
FANETTI, Matthew et al. Forensic Child Psychology: Working in the Courts and Clinic. New Jersey: John Wiley \& Sons, 2015.

FAWCETT, Jonathan et al. Of guns and geese: a meta-analytic review of the 'weapon focus' literature. Psychology, Crime \& Law, p. 1-32, 2011. Disponível em: https://www.researchgate.net/publication/233325637_Of_guns_and_geese_A_metaanalytic_review_of_the_'weapon_focus'_literature. Acessado em: 27.3.2018.

FISHER, Ron P. BRENNAN, K. MCCAULEY, M. R. The cognitive interview method to enhance eyewitness recall. Memory and suggestibility in the forensic interview, p. 265286, 2002.

FORD, Elizabeth. AGGARWAL, Neil. Neuroethics of Functional Neuroimaging in the Courtroom. In: SIMPSON, Joseph R. (Ed.). Neuroimaging in Forensic Psychiatry: From the Clinic to the Courtroom. New Jersey: John Wiley \& Sons, p. 325-340, 2012.

FOREST, Marilyne. BLANCHETTE, Isabelle. Memory for neutral, emotional and traumarelated information in sexual abuse survivors. European Journal of Psychotraumatology, v. 9, p. 1-10, 2019.

FOTOPOLOU, Aikaterini. CONWAY, Martin A. SOLMS, Mark. Confabulation: motivated reality monitoring. Neuropsychologia, n. 47, p. 2180-2190, 2007.

FRENDA, S. J. et al. Sleep Deprivation and False Memories. Psychological Science, v. 25, n. 9, p. 1674-1681, 2014.

GIOSTRA, Glauco. La testimonianza del minore: tutela del dichiarante e tutela dela verità. Rivista Italiana di Diritto e Procedura Penale, v. 3, p. 1019-1028, 2005.

GLOECKNER, Ricardo Jacobsen. Depoimento sem dano? Das funções não declaradas ao regime de heteroveridição no processo penal. Revista Liberdades, n. 22, p. 128-143, mai.ago. 2016.

GOLDSTEIN, M. Decade of the brain. An agenda for the nineties. West J Med, v. 161, n. 3, p. 239-241, 1994.

GUDJONSSON, Gisli $\mathrm{H}$. The Psychology of Interrogations and Confessions: A Handbook. West Sussex: John Wiley \& Sons, 2003. 
HAAM, Juhee. YAKEL, Jerrel L. Cholinergic modulation of the hippocampal region and memory function. J Neurochem, v. 142, suppl. 2, p. 111-121, Ago. 2017.

HARRISON, P. J. The hippocampus in schizophrenia: a review of the neuropathological evidence and its pathophysiological implications. Psychopharmacology, v. 174, n. 1, p. 151-162, jun. 2004

HASSEMER, Winfried. Neurociência e culpabilidade em Direito Penal. Revista Brasileira de Ciências Criminais, vol. 100, São Paulo: Ed. RT, 2013.

HAWARD, Lionel R. C. Alguns aspectos psicológicos da prova testemunhal. Revista Brasileira de Criminologia e Direito Penal, Rio de Janeiro, v. 2, n. 5, p. 17-35, abr./jun. 1964.

HOSCHEIDT, Siobhan M. et al. Encoding negative events under stress: High subjective arousal is related to accurate emotional memory despite misinformation exposure. Neurobiology of Learning and Memory, v. 112, p. 237-247, 2014.

HOWE, Mark L. KNOTT, Lauren M. The fallibility of memory in judicial processes: Lessons from the past and their modern consequences. Memory, v. 23, n. 5, p. 633-656, 2015.

INDA ORTIZ DE ZARATE, Francisco Javier. Testimonio, psicologia y ley. Eguziklore: zientzia kriminologikoen aldizkari elektronikoa, n. 15, p. 215-248, 2001.

IZQUIERDO, Ivan. Memória. Porto Alegre: Artmed, 2018.

JAEGER, Antonio et al. Human Memory research: Current hypotheses and new perspectives. Estudos de Psicologia, v. 21, n. 2, p. 92-103, abr.-jun. 2016.

JONES, Owen D. et al. Law and neuroscience: recommendations submitted to the President's Bioethics Commission. Journal of Law and the Biosciences, p. 224-236, march $31^{\text {st }}, 2014$.

KALINSKY, Beatriz. Los testigos son los ojos de los jueces: la formación de creencias em los processos penales. Cuadernos de doctrina y jurisprudência penal: criminologia, teoria y praxis, v. 1, n. 1, p. 119-132, 2002.

KANDEL, Eric R. et al. Princípios de Neurociências. Porto Alegre: AMGH, 2014. 
KELLOGG, Ronald T. Fundamentals of cognitive psychology. Thousand Oaks: Sage Publications, 2007.

KENNEDY, Mary B. Synaptic Signaling in Learning and Memory. Cold Spring Harb Perspect Biol, p. 1-16, 2016.

KERSTEN, Alan W. EARLES, Julie L., UPSHAW, Christin. False recollection of the role played by an actor in an event. Mem Cognit, v. 41, n. 8, p. 1144-1158, nov. 2013.

KIHLSTROM, John F. DORFMAN, Jennifer. PARK, Lillian. Implicit and Explicit Memory and Learning. In: VELMANS, Max. SCHNEIDER, Susan (Eds.). The Blackwell Companion to Consciousness. Hoboken: Blackwell Publishing, p. 525-539, 2007.

KOESTLER, Arthur. The Ghost in the Machine. London: Hutchinson, 1967.

KRAUSE, Adam J. et al. The sleep-deprived human brain. Nat Ver Neurosci, v. 18, n. 7, p. 404-418, jul. 2017.

KUHN, Thomas S. A estrutura das revoluções científicas. São Paulo: Perspectiva, 1975.

LACY, Joyce W. STARK, Craig E. L. The Neuroscience of Memory: Implications for the Courtroom. Nat Rev Neurosci, n. 14, v. 9, p. 649-658, sept. 2013.

LENT, Roberto. Cem bilhões de neurônios? Conceitos fundamentais de neurociência. São Paulo: Atheneu, 2010.

LOPES, Mariângela Tomé. O reconhecimento como meio de prova: Necessidade de reformulação do direito brasileiro. Tese (Doutorado). Faculdade de Direito da Universidade de São Paulo. São Paulo, 2011. Reconhecimento de pessoas e coisas como meio de prova irrepetível e urgente. Necessidade realização antecipada. Boletim IBCCRIM, Ano XIX, n. 229, p. 6-7, dez. 2011.

LOPES JUNIOR, Aury. DI GESU, Cristina Carla. Falsas memórias e prova testemunhal no processo penal: em busca da redução de danos. Revista de Estudos Criminais, v. 7, n. 25, p. 59-69, abr.-jun. 2007. 
LOFTUS, Elizabeth F. ZANNI, Guido. Eyewitness testimony: the influence of the wording of a question. Bulletin of the Psychonomic Society, v. 5, n. 1, p. 86-88, 1975.

. Creating False Memories. Scientific American, p. 70-75, sept. 1997.

. Memory. Reading: Addison-Wesley, 1980.

LUNDY-EKMAN, Laurie. Neurociências: fundamentos para reabilitação. Rio de Janeiro: Elsevier, 2008.

LUUS, C. A. Elizabeth. WELLS, Gary L. The Malleability of Eyewitness Confidence: CoWitness and Perseverance Effects. Journal of Applied Psychology, v. 79, n. 5, p. 714-723, 1994. Disponível em: http://public.psych.iastate.edu/glwells/Wells\%20pdfs/199099/Luus_\%26\%20Wells_1994\%20_JAP.pdf. Acessado em: 27.3.2018.

LYNN, Steven Jay et al. What Do People Believe About Memory? Implications for the Science and Pseudoscience of Clinical Practice. Canadian journal of psychiatry. Revue canadienne de psychiatrie, v. 60, n. 12, p. 541-547, 2015.p. 543.

MAIER, Jonathan G. NISSEN, Cristoph. Sleep and memory: mechanisms and implications for psychiatry. Curr Opin Psychiatry, v. 30, n. 6, p. 480-484, nov. 2017.

MAJERUS, Steve. VAN DER LINDER, Martial. Memory disorders in children. Handbook of Clinical Neurology, v. 111, Pediatric Neurology Part I, chapter 27, p. 1-6, 2013.

MALATESTA, Nicola Framarino. A Lógica das Provas em Matéria Criminal. São Paulo: Conan Editora, 1995. v. 2.

MARQUES, Mateus. Algumas inquietações sobre as contribuições da neurociência em relação aos fins do direito penal. Revista Síntese de direito penal e processual penal, v. 15, n. 92, p. 108-139, jun.-jul. 2015.

MATILDA, Janaina. Standards de prova: a modéstia necessária a juízes na decisão sobre os fatos. Disponível em: https://www.academia.edu/37511922/Matida_2018_Standards_de_prova_a_mod\%C3\%A9 stia_necess \%C3\%A1ria_a_ju\%C3\%ADzes_na_decis\%C3\%A3o_sobre_os_fatos.pdf. Acessado em: 05.04.2019.

MIGUELES, Malen. GARCIA-BAJOS, Elvira. Recall, recognition, and confidence patterns in eyewitness testimony. Applied Cognitive Psychology, v. 13, n. 3, p. 257-268, jun. 1999. Disponível em: http://onlinelibrary.wiley.com/doi/10.1002/(SICI)1099- 

27.3.2018.

MILNER, Brenda. SQUIRE, Larry R. KANDEL, Eric. Cognitive Neuroscience and the Study of Memory. Neuron, v. 20, p. 445-468, mar. 1998. p. 447.

MINISTÉRIO DA JUSTIÇA. Avanços científicos em psicologia do testemunho aplicados ao reconhecimento pessoal e aos depoimentos forenses. Série Pensando o Direito, n. 59, 2015 .

MIRA Y LÓPEZ, E. Manual de psicologia jurídica. São Paulo: Vida Livros, 2009.

MLODINOW, Leonard. Subliminar - como o inconsciente influencia nossas vidas. Rio de Janeiro: Zahar, 2018.

MURPHY, Gillian. GREENE, Clara M. Perceptual Load Affects Eyewitness Accuracy and Susceptibility to Leading Questions. Frontiers in Psychology, 7, article 1322, aug. 2016.

NADER, Karim. Reconsolidation and the Dynamic Nature of Memory. Cold Spring Harb Perspect Biol, v. 7, n. 10, a021782, out. 2015. Disponível em: https://www.ncbi.nlm.nih.gov/pmc/articles/PMC4588064/. Acessado em: 20.03.2019.

NATIONAL RESEARCH COUNCIL OF THE NATIONAL ACADEMIES. Identifying the Culprit: Assessing Eyewitness Identification. Washington, D.C.: The National Academy Press, 2014.

NICHD. Guião de entrevista forense do NICHD. Disponível em: http://nichdprotocol.com/nichdportuguese.pdf. Acessado em: 11.03.2019.

NOË, Alva. Inattentional Blindness, Change Blindness, Consciousness. In: VELMANS, Max. SCHNEIDER, Susan (Eds.). The Blackwell Companion to Consciousness. Hoboken: Blackwell Publishing, p. 504-511, 2007.

PARDO, Michael S. PATTERSON, Dennis. Minds, Brains, and Law. The conceptual Foundations of Law and Neuroscience. Nova Iorque: Oxford University Press, 2013.

PAUlO, R. M. ALBUQUERQUE, P. B. BULL, R. A entrevista cognitiva melhorada: pressupostos teóricos, investigação e aplicação. Psicologia, v. 28, n. 2, p. 21-30, dez. 2014. 
Disponível em http://www.scielo.mec.pt/scielo.php?script=sci_arttext\&pid=S087420492014000200003\&lng=pt\&nrm=iso. Acessado em: 17.08.2018.

PEIXOTO, Carlos Eduardo. RIBEIRO, Catarina. ALBERTO, Isabel. O protocolo de entrevista forense do NICHD: contributo na obtenção do testemunho da criança no contexto português. Revista do Ministério Público de Lisboa, v. 34, n. 134, p. 149-197, abr.-jun. 2013.

PESSOA, Fernando. Obra poética. Rio de Janeiro: Aguilar, 1965.

PETTERSON, Bianca. PATERSON, Helen M. Culture and Conformity: The effects of independent and interdependent self-construal on witness memory. Psychiatry, Psychology and Law, p. 1-10, 2012.

PEZDEK, Kathy. ROE, Chantal. The Suggestibility of Children's Memory of Being Touched: Planting, Erasing and Changing Memories. Law and Human Behavior, v. 21, n. 1, p. 95-106, February $1997 . \quad$ Disponível em: http://www.cgu.edu/include/The\%20Suggestibility\%20of\%20Children's\%20Memory \%20for.pdf. Acessado em: 25.7.2016.

PICKEL, Kerri L. STALLER, Josua B. A perpetrator's accent impairs witness' memory for physical appearance. Law and Human Behavior, v. 36, n. 2, p. 140-150, 212.

PONTE, Antonio Carlos da. Falso testemunho no processo. São Paulo: Atlas, 2000.

PURVES, Dale et al. (Eds.). Neuroscience. Sunderland: Sinauer, 2008.

RASSI, João Daniel. Neurociência e prova no processo penal: Admissibilidade e valoração. Tese (Doutorado). Faculdade de Direito da Universidade de São Paulo. São Paulo, 2017.

RIBA, J. et al. Telling true from false: cannabis users show increased susceptibility to false memories. Molecular Psychiatry, v. 20, p. 772-777, 2015.

RICHARDS, Blake A. FRANKLAND, Paul W. The Persistence and Transience of Memory. Neuron, v. 94, n. 6, p. 1071-1084, 21 de junho de 2017.

ROCA, Miquel et al. Cognitive impairments and depression: a critical review. Actas Esp Psiquiatr, v. 43, n. 5, p. 187-193, 2015. 
ROMERO COLOMA, Aurelia Maria. La valoración judicial de la prueba testifical y la psicologia del testimonio. Actualidad Penal, v. 2, 27/48, p. 791-805, semanal 1998.

ROSS, David R. et al. Unconscious Transference and Mistaken Identity: When a Witness Misidentifies a Familiar but Innocent Person. Journal of Applied Psychology, v. 79, n. 6, p. 918-930, December 1994. Disponível em: https://www.researchgate.net/publication/232508696_Unconscious_Transference_and_Mis taken_Identity_When_a_Witness_Misidentifies_a_Familiar_but_Innocent_Person. Acessado em: 27.3.2018.

SANTOS, Benedito Rodrigues dos. GONÇALVES, Itamar Batista. VASCONCELOS, Gorete (Orgs.). Escuta de crianças e adolescentes em situação de violência sexual: aspectos teóricos e metodológicos: guia para capacitação em depoimento especial de crianças e adolescentes. Brasília: EdUCB, 2014.

SARAIVA, Renan Benigno et al. Conformidade entre testemunhas oculares: efeitos de falsas informações nos relatos criminais. Psico-USF, v. 20, n. 1, p. 87-96, jan.-abr. 2015.

SAUERLAND, Melanie et al. Stress stress-induced cortisol responses and eyewitnesses identification performance. Behavioral Sciences and the Law, v. 34, p. 580-584, 2016.

SCHACTER, Daniel L. Constructive memory: past and future. Dialogues in Clinical Neuroscience, v. 14, n. 1, p. 7-18, 2012.

Rocco, 2003. Os sete pecados da memória: como a mente esquece e lembra. Rio de Janeiro:

SCHOOLER, Jonathan W. ENGSTLER-SCHOOLER, Tonya Y. Verbal Overshadowing of Visual Memories: Some Things Are Better Left Unsaid. Cognitive Psychology, n. 22, p. 36-71, $1990 . \quad$ Disponível em: http://wixtedlab.ucsd.edu/publications/Psych\%20272/Schooler_Engstler-

Schooler_1990.pdf. Acessado em: 27.3.2018.

SERRANO, Peter et al. PKM $\zeta$ Maintains Spatial, Instrumental, and Classically Conditioned Long-Term Memories. PLoS Biol, v. 6, n. 12, e318, 2008. Disponível em: https://journals.plos.org/plosbiology/article?id=10.1371/journal.pbio.0060318. Acessado em: 20.03.2019.

SHAW, Julia. PORTER, Stephen. Constructing Rich False Memories of Commiting Crime. Psychological Science OnlineFirst, p. 1-11, 14 jan. 2015. Disponível em: 
http://nebula.wsimg.com/ce2babe46721a32c861f1a646c2836aa?AccessKeyId=AF62ECFB CD8F6D95BACE\&disposition=0\&alloworigin=1. Acessado em: 20.03.2019.

WOODWORTH, Michael. Are the misinformed more punitive? Beliefs and misconceptions in forensic psychology. Psychology, Crime \& Law, p. 1-20, 2013.

SIMONS, Daniel J. CHABRIS, Christopher F. Gorillas in our midst: sustained inattentional blindness for dynamic events. Perception, v. 28, p. 1059-1074, 1999. Disponível em: http://www.chabris.com/Simons1999.pdf. Acessado em: 27.3.2018.

STEIN, Lilian Milnitsky. NYGAARD, Maria Lúcia Campani. A memória em julgamento: uma análise cognitiva dos depoimentos testemunhais. Revista Brasileira de Ciências Criminais, v. 11, n. 43, p. 151-164, abr./jun. 2003.

. FEIX, Leandro da Fonte. Contribuições da psicologia cognitiva para a oitiva da testemunha: avaliando a eficácia da entrevista cognitiva. Revista Brasileira de Ciências Criminais, v. 14, n. 61, p. 147-180, jul.-ago. 2006.

MEMON, Amina. Testing the Efficacy of the Cognitive Interview in a Developing Country. Applied Cognitive Psychology, v. 20, n. 5, p. 597-605, 2006.

TARUFFO, Michele. Proceso y neurociencia. Aspectos generales. In: TARUFFO, Michele; FENOLL, Jordi Nieva (Orgs.). Neurociencia y processo judicial. Madrid: Marcial Pons, 2013.

THE ROYAL SOCIETY. Neuroscience and the Law. Brainwaves, v. 4, dec. 2011.

TORNAGHI, Alberto. Da prova testemunhal e do valor que se lhe deve prestar. Revista de Direito Penal, v. 29, p. 221-229, mai.-out. 1940.

TURGEON, Jeannine. FRANCIS, Elizabeth. LOFTUS, Elizabeth. Crafting Model Jury Instructions for Evaluating Eyewitness Testimony. The Pennsylvania Lawyer, p. 50-52, set.-out./2014.

TWIDDY, Anna. The Little Rascals Case: A Case for Regulating Children's Testimony. PIT Journal, n. 7, 2016. Disponível em: http://pitjournal.unc.edu/article/little-rascals-casecase-regulating-children\%E2\%80\%99s-testimony. Acessado em: 09.01.2019.

UNDEUTSCH, Udo. KLEIN, Gisela. Dicho de buena fe, pero falso. De la problemática del valor probatório de la declaración testimonial. Revista de derecho penal y processo penal, n. 9, p. 1534-1541, set. 2011.

VANN, S. D. Re-evaluating the role of the mammillary bodies in memory. Neuropsychologia, v. 48, n. 8, p. 2316-2327, jul. 2010. 
VIANNA, Mônica R. M. et al. Short- and Long-term memory: Differential involvement of neurotransmitter systems and signal transduction cascades. An. Acad. Bras. Ci., v. 72, n. 3, p. 353-364, 2000.

VILBERG, Kaia L. RUGG, Michael D. Memory retrieval and the parietal cortex: a review of evidence from a duel-process perspective. Neuropsychologia, v. 46, p. 1787-1799, 2008.

VITALE, Barbara. Le influenze del trauma sulla testimonianza. In: GIANINI, Ana Maria. CIRILLO, Francesco. Itinerari di vittimologia. Milano: Giuffrè, p. 403-407, 2012.

VONMOOS, Matthias et al. Cognitive Impairment in Cocaine Users is Drug-Induced but Partially Reversible: Evidence from a Longitudinal Study. Neuropsychopharmacology, v. 39, n. 9, p. 2200-2210, Ago. 2014. Disponível em: https://www.ncbi.nlm.nih.gov/pmc/articles/PMC4104339/. Acessado em: 08.3.2019.

WALTON, Douglas. Witness Testimony Evidence: Argumentation, Artificial Intelligence, and Law. Cambridge: Cambridge University Press, 2008.

WEISBERG, Deena Skolnic et al. The seductive allure of neuroscience explanations. Journal of Cognitive Neuroscience, v. 20, 2008. Disponível em: https://www.ncbi.nlm.nih.gov/pmc/articles/PMC2778755/. Acessado em: 08.01.2019.

WERNER, Nicole-Simone. KÜHNEL, Sina. MARKOWITSCH, Hans J. The neuroscience of face processing and identification in eyewitnesses and offenders. Frontiers in Behavioral Neuroscience, v. 7, article 189, p. 1-12, 06 dec. 2013.

WESTERLINDH, Carlos Prat. Nuevos detectores de mentiras y derecho penal. La Ley Penal - Revista de Derecho Penal, Procesal y Penitenciario, n. 84, p. 30-36, jul.-ago. 2011.

WISE, Richard A. et al. An examination of the causes and solutions to eyewitness error. Frontiers in Psychiatry, v. 5, article 102, p. 1-8, 13 aug. 2014.

YUILLE, J. C. et al. Interviewing children in sexual abuse cases. In: GOODMAN, G. S. BOTTOMS, B. L. (Eds.). Child victims, child witness: Understanding and improving testimony. New York: Guilford Press, p. 95-115, 1993. 


\section{ANEXO I}

O ora apelante foi denunciado pela prática de atentado violento ao pudor (art. 214, caput, c.c. o art. 224, alínea "a", e art. 226, inciso II, todos do Código Penal) em razão de fato ocorrido no dia 27 de abril de 2001, por volta das 23h, na Rua xxx, $n^{\circ} 190$, Vila xxx, naquela Comarca, quando teria constrangido Tauane xxx, à época com cinco anos de idade, mediante violência presumida, a permitir que com ela praticasse ato libidinoso diverso da conjunção carnal. Narra a denúncia que o ora apelante, no dia dos fatos, aproveitando-se da condição de companheiro da avo materna da vítima, cujas residências compartilhavam o mesmo quintal, entrou na casa desta última, tirou sua roupa e colocou a boca na vagina da criança, chegando a mordê-la.

Foi condenado a seis anos de reclusão, no regime integralmente fechado, como incurso no art. 214, caput, c.c. o art. 224, alínea "'a", todos do Código Penal (fls. 175-186).

Apela da sentença, buscando a absolvição, argumentando com o resultado negativo do exame de corpo de delito e a alteração no depoimento da mãe da vítima em razão desse resultado, mostrando-se nítida a intenção em prejudicá-lo.

Alternativamente, pugna pela fixação de regime mais brando para iniciar o cumprimento da pena, possibilitando a progressão (fls. 203-207).

Contra-razões a fls. 211-214.

A Douta Procuradoria Geral de Justiça oficia no sentido do não provimento do recurso (fls. 220-223).

É o relatório.

É das mais difíceis a tarefa do juiz, quando deve prestar jurisdição em processos como este. A severa imputação de crime não se faz amparar por qualquer prova objetiva e sequer 
há testemunho visual do delito, como, aliás ocorre, de ordinário, em situações como a relatada nestes autos.

Conforme informação da mãe, tomara conhecimento do fato no dia em que, chegando ã. residência de volta do trabalho, encontrara a filha segurando uma moeda de cinquenta centavos e, perguntada sobre como teria conseguido tal dinheiro, a criança relatou que o recebera do acusado e, depois, chorando, teria informado que este tirara suas roupas e colocado a boca em sua vagina (fl.126).

É de se observar, entretanto, que a vítima era de tenra idade, apenas cinco anos e, por isso, seria - conforme descreve a informação da psicóloga que primeiro a atendeu - criança inocente, singela, sem malícia ou perspicácia (fl. 32). Se assim era, é possível que não pudesse formular juízos normativos acerca de comportamentos sexuais e, para que reagisse de modo espontâneo, informando que o acusado lhe tirara a roupa e colocara a boca em sua vagina - palavra que por certo não usaria - não se comportaria nervosamente, chorando, como se soubesse que algo grave e proibido tivesse ocorrido. Talvez reagisse de outro modo, se não houvesse, qualquer influência de adulto inquirindo-a sugestivamente e, relatando o fato, o faria de modo natural, mencionando a pessoa - que, aliás, não lhe era estranha, pois convivia com a avó há mais de quinze anos - a teria beijado ali, apontando o lugar. Talvez até revelasse curiosidade acerca do comportamento, pois acostumada a receber beijos em outras partes do corpo, fora surpreendida com a nova modalidade de carícia.

Entretanto, se a partir da posse de uma moeda, a mãe já a inquirira acerca da origem, possivelmente sugerindo pela conduta e entonação de voz que algo grave poderia ter ocorrido, é certo que a criança ficasse assustada e reagisse nervosamente, até mesmo chorando. A partir daí, perguntas sugestivas acerca do que fizera o acusado, se lhe tocara o corpo, se mexera em sua vagina ou algo assim, poderiam ter conduzido a respostas afirmativas, porque essa é a reação infantil normal, concordar com o adulto em situações estressantes, percebendo que deve assentir às sugestões, pois se imagina sob censura e ameaçada pelo comportamento.

Estudos sobre o tema, relatados por Edmond Picard, citado pelo prof. Hélio Gomes, "refletindo o pensamento geral dos autores, apresenta as seguintes recomendações 
relativamente ao depoimento infantil: 1c) É preciso por extrema circunspeção nas inquirições feitas a crianças: uma pergunta, uma atitude, uma ameaça, tem no que lhes diz respeito, o alcance de verdadeira sugestão, podendo induzi-las a mentir; 2c) uma criança que comparece ante a justiça, depois de haver sido interrogada por seus pais, por vizinhos, por agentes subalternos, não oferece garantias; suas declarações podem ser admitidas apenas a título de informações muito frágeis; 3c) nos casos, muito raros, em que a criança seja inquirida primeiramente por um juiz experimentado e prudente, cumpre não lhe fazer nenhuma pergunta sem que se precisem os fatos podendo sugerir respostas; é preciso deixar que a criança exponha por si mesma; 4c) os dizeres de uma criança, quaisquer que sejam, não podem ser admitidos de plano, exigem a mais severa verificação analítica, postos em confronto com as circunstâncias exteriores, quer com as que possam contradizêlos, quer com as que possam confirma-los".

Daí as conclusões do psicólogo Daniel L. Schacter ao relatar rumoroso caso havido numa creche americana, onde se suspeitou que dezenas de crianças tivessem sido molestadas por alguém que ali trabalhava: "Os erros cometidos nas entrevistas da década de 1980 também são responsáveis por novas pesquisas nos anos 90, que deverão trazer benefícios para as crianças e o resto da sociedade". E logo depois: "Entrevistadores que recorrem a perguntas simples, abertas e evitam técnicas arriscadas usadas no passado têm uma excelente oportunidade de conseguir informações corretas até mesmo de testemunhas de tenra idade".

Segundo conclusões das pesquisas então realizadas, "recordações espontâneas de crianças tendem a ser corretas, enquanto suas respostas a perguntas especificas são mais suscetíveis de conter distorções". Anotou-se que, na forma como realizadas as entrevistas iniciais, se estas não produziam respostas satisfatórias, as crianças da Creche Fells Acres eram entrevistadas em diversas outras ocasiões e os resultados eram bastante parecidos: a princípio não se reportavam a molestamento e, por fim, acabavam admitindo haver sido tocadas, ou seja: "respostas negativas acabavam sendo substituídas por respostas positivas".

Isso levou os pesquisadores a entender como alarmante o resultado, pois estudos conduzidos pelos psicólogos, demonstraram que, quando crianças são entrevistadas duas vezes e dão detalhes na segunda entrevista que não foram mencionados na primeira, existe grande probabilidade de que os novos detalhes sejam imprecisos. 
Ressaltou-se, ainda, a vulnerabilidade básica do sistema de memória das crianças: "Quando são indagadas repetidamente sobre eventos especificas, podem começar a achar que os incidentes são familiares porque foram mencionados várias vezes. E uma vez que não têm lembranças detalhadas da fonte dessa sensação de familiaridade, as crianças em idade préescolar podem começar a misturar trechos e partes de diferentes episódios do passado, ou mesmo incluir elementos de fantasia e imaginação em suas recordações. Os problemas de fonte de memória explicariam porque os pais podem, inadvertidamente, sugerir para as crianças, experiências que na verdade nunca aconteceram.".

Em processos como este, onde graves acusações são feitas a alguém, fundadas em depoimento infantil que poderia ter sofrido sugestionabilidade, é altamente temerária a condenação, assentada em relatos que, em princípio, teriam sido colhidos sem qualquer técnica. Depois, levada a criança para profissionais respeitáveis, que se dispunham a ouvila sobre o fato, estes já estariam trabalhando sobre lembranças calcadas na memória infantil e seria preciso técnica e especialização específicas, além de pacientes estudos envolvendo todo o núcleo familiar - para que se pudesse formular juízos de valores sobre o relato.

A despeito da elogiável atenção dedicada pelo juízo e promotoria de justiça a este processo, a instrução padeceu da precariedade dos meios técnicos de que se serve o Poder Judiciário.

À míngua de profissionais próprios para esse tipo de investigação, serviu-se da dedicada boa vontade de órgãos externos, mais afeitos ao tratamento de incontestes vítimas de violência sexual, que à pesquisa da verdade sobre depoimentos infantis. Isso se infere no relatório do Centro de Referência As Vítimas de Violência, cujo auxílio foi solicitado no processo.

A princípio acentuou-se a dificuldade de contatos com a mãe e a criança, porque obstáculos advindos do trabalho materno impediam-nas de comparecer. Depois, formulouse, apenas, hipótese sobre o ocorrido, dispondo-se textualmente: "Por todo o processo que Tauane tem passado, levantamos a hipótese de que esta criança apresenta-se intimidada com as consequências advindas de sua revelação. Temerosa com o que pode vir a 
acontecer e dispõe de defesa bastante comum entre as crianças, que diferentemente dos adultos, não tem nenhum controle da situação, buscando o fechamento, o isolamento como modo de sobrevivência. Tal forma de lidar com o trauma também é reconhecido naqueles que são os responsáveis pelas crianças vitimadas, uma vez que existe em muitos casos um sentimento de culpabilização principalmente da mãe de filhas que sofreram abuso sexual. Devido a esse sentimento, é também de grande importância que esta mãe seja acompanhada terapeuticamente para que Tauane possa progredir em maior facilidade".

Como se lê adiante, naquele relatório, não se reportou ali a qualquer técnica investigativa especializada. Como centro de tratamento de vítimas evidentes de violência, os subscritores ressaltam: "O CNRVV tem como norte em todos os casos o acreditar na palavra da criança ou adolescente e, uma vez que Tauane já expôs sua história à mãe, avó, tia e, também, à psicóloga anteriormente designada para averiguação dos fatos, acreditamos que o processo legal pode ter andamento, mais importante é que cuidemos dessa criança, tão pequena e tão maltratada e abusada" (fl. 50).

Vale dizer, com o fato eventualmente ocorrido em abril de 2001, em outubro de 2002 somente restaria acreditar que o relato infantil fosse verdade e que se cuidasse do tratamento psicológico da mãe e filha. É confortador sob o aspecto humano da questão, contudo, nada contribuiu para a pesquisa da verdade, acerca da imputação motivadora do processo.

De outro lado, é certo que havia animosidade entre a mãe da criança e o ora apelante, como este sustentou, ao negar o delito. Ele convivera por década e meia com a mãe daquela primeira e, ao que parece, entre esta e o padrasto não teria havido convivência harmônica. Enquanto enteada, a mãe de Tauane acusava o réu de tê-la molestado quando era criança, embora nada houvesse dito a ninguém, até o incidente motivador deste processo (fl. 127).

Não se pode formular seguro juízo de valor acerca, também, dessa informação. Não raro filhos culpam os estranhos que invadem a relação familiar, atribuindo-lhes a responsabilidade pela família original desfeita e são capazes de projetar-lhes sentimentos de vívida repulsa, embora possam não evidenciá-los claramente. Com o tempo, podem, inconscientemente, rememorar algum episódio passado e alterar a lembrança do fato para a punição do aparente culpado. Relatos de memórias resgatadas de molestamento sexual, 
dentro do núcleo familiar, foram situações recorrentes na década a partir de 1980, com revelação posterior dos diversos equívocos descobertos.

Estudos recentes de neurociência têm revelado a pouca precisão da memória, fundada em fatos ocorridos ainda há pouco tempo. A neurocientista brasileira, Suzana HerculanoHouzel, mestra pelo Case Westem Reserve University, nos Estados Unidos, doutora pela Université Paris VI e pesquisadora por quatro anos no Instituto Max-Planck, na Alemanha, atualmente no Museu da Vida, da Fundação Oswaldo Cruz, no Rio de Janeiro, afirma: "Que é possível lembrar do que não aconteceu não é novidade alguma" e adiante: "Como é passivei haver no cérebro um registro de algo que não aconteceu? A primeira razão é que o cérebro não é uma câmera de vídeo - lembrar não é reprisar a fita dos sentidos. Muito pelo contrário, aliás: acredita-se hoje em dia, que a memória é reconstituída a cada vez que é 'chamada', juntan.do lembranças distribuídas cérebro afora". E arremata explicando: "Acontece também que a imaginação, ou mais exatamente a visualização mental, o 'ver com os olhos da mente), usa exatamente os mesmos circuitos que a visão 'vinda de fora', e esses circuitos também fazem parte da memória. O que quer dizer que as visualizações mentais particularmente vívidas podem deixar traços indistinguíveis dos que seriam deixados pelo evento real".

Portanto, não seria impossível que a mãe da ofendida houvesse visualizado mentalmente fato que em verdade não ocorrera com ela, motivada pela conflituosa convivência anterior com o acusado. Poderia ter ouvido relatos de molestamentos infantis e os re-elaborara inconscientemente, como fatos vivenciados. O fenômeno é cuidado em psicologia como erro decorrente da criptominésia: "pessoas podem, de boa-fé, reproduzir de memória, escrita ou idéias de outros indivíduos e, inconscientemente, erradamente atribuir essas criações a si mesmas". A criptomnésia, associada ao sentimento de repulsa ao padrasto, poderiam tê-la induzido a uma falsa lembrança de molestamento por este e, depois, ao interrogar a filha sobre a moeda, de modo também inconsciente, passado a sugestionar respostas no interrogatório, levando ao resultado obtido.

É claro, todas essas observações, tal como no relatório do CNRVV acima mencionado, não passam de meras hipóteses acerca do ocorrido. Não se descarta, sequer, a possibilidade de que os depoimentos e demais informações colhidas no curso da ação sejam verídicas. 
Entretanto, não há elementos informadores seguros e estudos de confiabilidade técnica somente possíveis de se obter com criteriosa e alongada análise por profissionais especializados - ignorando-se a verdade real sobre os fatos motivadores deste processo.

Contudo, essa insegurança sobre a prova, a mera possibilidade não descartada pela psicologia, de que tudo pudesse decorrer de resgate de falsas memórias e erro pela falta de técnica no questionamento infantil, deve beneficiar a defesa. A dúvida deve ser causadora do non liquet, sendo altamente temerária a condenação, com ba.se em provas tão imprecisas, como a reunida nos autos.

Em face desses motivos, acolhe-se o apelo.

Assim, dá-se provimento ao recurso, para absolver o ora apelante, José Martins de Oliveira, nos termos do artigo 386, VI do CPP. 